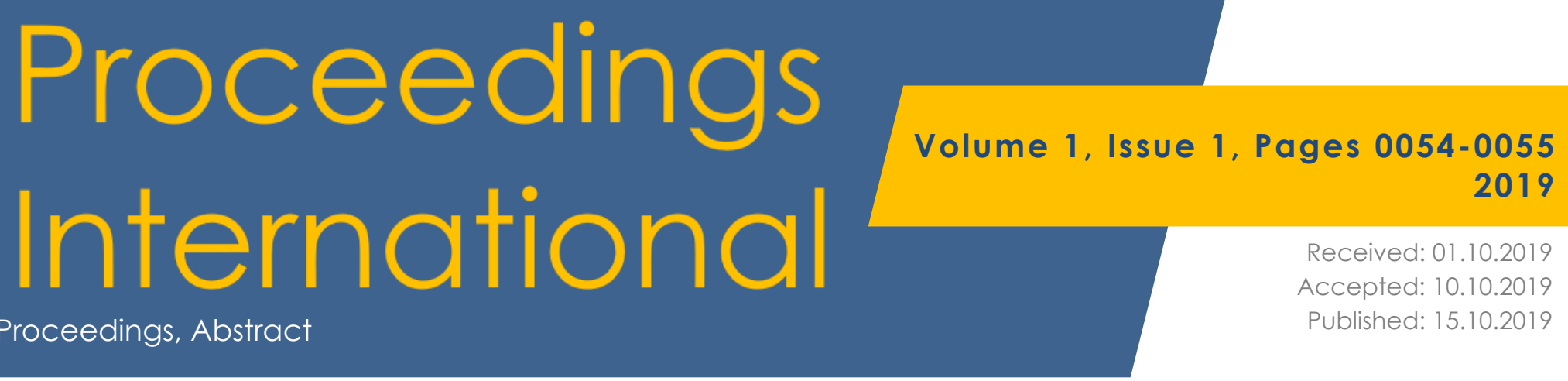

\title{
SEM investigations of Fe-doped ZnO powders
}

\author{
R. Trusca ${ }^{10}$, M. Cernea ${ }^{2}$, M. Enculescu 2, A.I, Nicoara ${ }^{1}$, T. Popescu ${ }^{2,}$ C. Trisca-Rusu ${ }^{3}$ \\ 1 Politehnica University of Bucharest, 1-7 Gh, Polizu, 011061, Bucharest, Romania \\ 2 National Institute of Materials Physics, Atomistilor 405A, P.O. Box MG-7, Bucharest-Magurele, 077125, Romania \\ 3 National Institute of Research and Development for Microtechnology, Erou Iancu Nicolae 126A, Voluntari, 077190 \\ * Correspondence: truscaroxana@yahoo.com; Scopus ID: 24529356300
}

Zinc oxide $(\mathrm{ZnO})$ is a semiconductor with a wide band gap $(\mathrm{Eg}=3.37 \mathrm{eV})$ and numerous applications as photo- catalysts, antibacterial agent, solar cells, gas sensors, etc [1, 2]. However, wide-band gap semiconductors are only activated under ultraviolet (UV) light irradiation, which limits their practical applications. The doping of various transition-metal cations or anions into wide-band gap semiconductors has been extensively studied to increase the visible-light absorption of these photocatalysts. In order to develop $\mathrm{ZnO}$ visible-light photocatalyst activity, $\mathrm{ZnO}$ was doped with $\mathrm{Fe} 3+$ because bulk-doped Fe(III) ions acts as visible-light absorbers. In the present study, we prepared $\mathrm{ZnO}$ doped with 0-3 at.\% Fe by hydrothermal method, in the absence and/or presence of a surfactant (CTAB) and, we investigated the as-obtained powders by X-ray diffraction, scanning electron microscope (SEM) and the photocatalytic tests on methylene blue $(\mathrm{MB})$ in both UV and visible spectral regions. As results, we found that the morphologic and photocatalytic properties of the two series of samples - iron doped $\mathrm{ZnO}$ with and without surfactant are in opposition. The photocatalytic activity in both UV and visible spectral region for the samples prepared without surfactant decreases as the iron content in samples increases while, an increase of the photocatalytic properties can be observed in the case of samples prepared with surfactant as the iron content increases, in agreement with UV-vis reflection measurements. Our results highlight the beneficial role of iron and surfactant on the photocatalytic properties of $\mathrm{ZnO}$ $[3,4]$.

Keywords: SEM, Fe-doped, $\mathrm{ZnO}$ powder, photocatalytic properties.

\section{Funding}

SEM analyses of the samples were facilitated by EU-funding grant POSCCE-A2-O2.2.1-2013-1/

Priority direction 2, Project No.638/12.03.2014, cod SMIS-CSNR 48652.

\section{Acknowledgments}

Not applicable.

\section{Conflicts of Interest}

The authors declare no conflict of interest. 

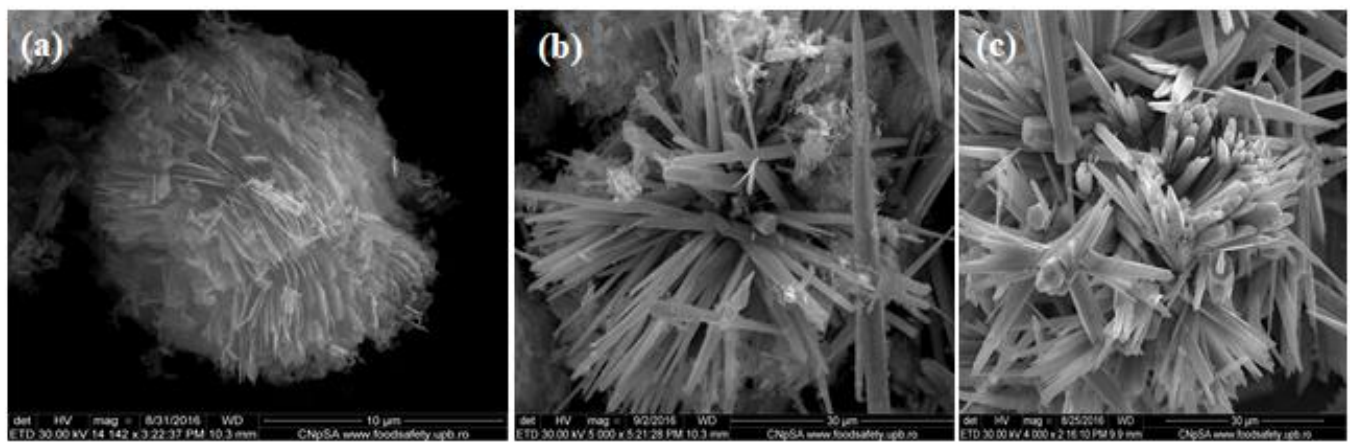

Figure 1. SEM images with various magnifications of A0 (a), A1 (b) and A3 (c) powders (without surfactant) dried at $200{ }^{\circ} \mathrm{C}, 2 \mathrm{~h}$ in air.
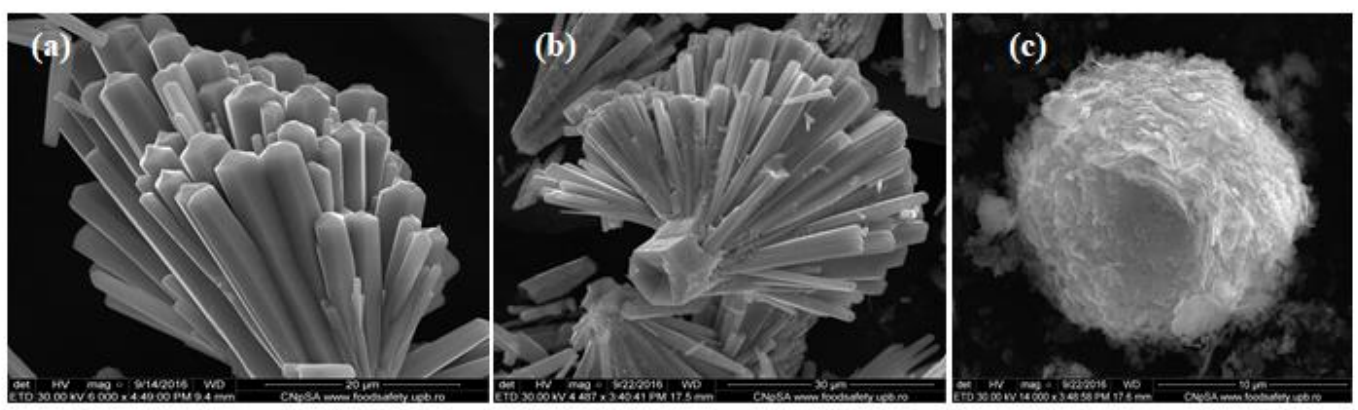

Figure 2. SEM images with various magnifications of A0,s (a), A1,s (b) and A3,s (c)-Ref.[3] powders (with surfactant) dried at $200{ }^{\circ} \mathrm{C}, 2 \mathrm{~h}$ in air.

\section{References}

1. Mang, A.; Reimann, K.; Rubenacke, S. Band gaps, crystal field splitting, spin-orbit coupling, and exciton binding energies in $\mathrm{ZnO}$ under hydrostatic pressure. Solid State Commun. 1995, 94, 251-254, https://doi.org/10.1016/0038-1098(95)00054-2

2. Yin, H.; Coleman, V.A.; Casey, P.S.; Angel, B.; Catchpoole, H.J.; Waddington, L.; McCall, M.J. A comparative study of the physical and chemical properties of nanosized $\mathrm{ZnO}$ particles from multiple batches of three commercial products. J.Nanoparticle Res. 2015, 17, 96-114, https://doi.org/10.1007/s11051-014$2851-y$.
3. Diamandescu, L.; Cernea, M.; Trusca, R.; Enculescu, M.; Tanase, L.; Baibarac, M.; Feder, M.; Nicoara, A.I.; Popescu, T. Effects of a surfactant on the morphology and photocatalytic properties of polycrystalline $\mathrm{Fe}$ doped ZnO powders. J. Phys. Chem. Solids. 2018, 121, 319-328, https://doi.org/10.1016/j.jpcs.2018.05.041.

4. Mihalache, M.; Cernea, M.; Pasuk, I. Relationship between ferromagnetism and, structure and morphology in un-doped $\mathrm{ZnO}$ and Fe-doped $\mathrm{ZnO}$ powders prepared by hydrothermal route. Curr. Appl. Physics. 2017, 17, 1127-1135, https://doi.org/10.1016/j.cap.2017.03.020.

(C) 2019 by the authors. This article is an open access article distributed under the terms and conditions of the Creative Commons Attribution (CC BY) license (http://creativecommons.org/licenses/by/4.0/). 